\title{
FORMULASI SEDIAAN LIPBALM DARI EKSTRAK BIJI KOPI ARABIKA (Coffea Arabica L.) JAVA PREANGER SEBAGAI EMOLIEN
}

\author{
Retty Handayani*, Framesti Frisma Sriarumtias, Sindi Sukmawati Sofwan
}

Program Studi Farmasi Fakultas MIPA Universitas Garut

\section{Info Article}

Submitted :

12 Agustus 2020

Revised :

14 November 2020

Accepted :

14 November 2020

Corresponding Author :

Retty Handayani

\section{Email :}

rettyhandayani@gmail.com

\section{ABSTRAK}

Sediaan lipbalm merupakan bentuk sediaan kosmetik dekoratif untuk melembabkan bibir. Salah satu komponen terpenting dari sediaan lipbalm adalah emolien. Asam linoleate dalam ekstrak biji kopi memiliki kelebihan sebagai emollient alami yang aman serta dapat menutupi bagian kulit yang kering dengan butiran lemak yang dikandungnya sehingga kulit bibir menjadi lunak dan lembab. Penelitian ini bertujuan untuk membuat formulasi sediaan lipbalm yang mengandung ekstrak biji kopi arabika (Coffea Arabica L). Sediaan lipbalm dibuat dengan variasi konsentrasi ekstrak kopi $3 \%, 6 \%$ dan $9 \%$. Formula yang dihasilkan kemudian dievaluasi stabilitasnya secara fisik. Uji iritasi dilakukan dengan metoda patch test, Uji efektivitas emolien menggunakan alat skin analyzer. Hasil penelitian menunjukan bahwa variasi konsentrasi ekstak kopi yang digunakan (3\%, 6\% dan 9\%) menunjukan bahwa konsentrasi $9 \%$ lebih stabil. Hasil uji iritasi menunjukan bahwa ketiga formula aman digunakan. Berdasarkan hasil uji efektivitas menunjukan bahwa formula dengan konsentrasi 9\% memberikan efek emolien yang baik setelah penggunaaan berdasarkan uji statistik metode paired samples T-test.

Kata kunci: emolien, ekstrak biji kopi, formulasi, lipbalm

\section{Access this article}

\section{ABSTRACT}

Lipbalm preparations are decorative cosmetic dosage forms to moisturize the lips. One of the most important components of lipbalm preparations is an emollient. The linoleic acid in coffee bean extract has the advantage of being a natural emollient that is safe and can cover dry skin with the fat it contains so that the lips become soft and moisturised. This study aims to make a lipbalm formulation containing extracts of Arabica coffee beans (Coffea Arabica L). Lipbalm preparations made with variations in the concentration of coffee extract 3\%, $6 \%$ and $9 \%$. The resulting formula is then evaluated for its physical stability. The irritation test is carried out using the patch test method, testing the effectiveness of emollients using a skin analyzer. The results showed that variations in the extract of coffee used $(3 \%, 6 \%$ and $9 \%)$ showed that the concentration of $9 \%$ was more stable. The irritation test results show that all three formulas are safe to use. Based on the results of the effectiveness test shows that the formula with a 
concentration of $9 \%$ gives a good emollient effect after use based on statistical tests the paired samples T-test method.

Keywords: emollients, coffee bean extracts, formulation, lipbalm

\section{PENDAHULUAN}

Lipbalm merupakan suatu sediaan yang digunakan untuk melembabkan bibir sehingga menjaga kesehatan bibir agar tetap lembab dan menambah nilai estetika (Putra S dan Ferry Y, 2015). Formulasi lipbalm dibuat dengan basis yang sama dengan basis lipstick namun tanpa warna sehingga terlihat transparan (Yusuf, 2019). Bahan utama dalam formulasi sediaan lipbalm adalah emolien dan pembawa sediaan lipbalm (Nazliniwaty, 2019).

Emolien dalam sediaan lipbalm bertujuan untuk melembabkan bibir dengan cara mempertahankan hidrasi, mencegah kekeringan dan kerusakan kulit akibat sinar matahari dan mencegah penguapan air dari kulit dengan membentuk lapisan pelindung sehingga membantu kelembaban kulit (Agustiana, 2019).

Emolien dari bahan sintetik memiliki beberapa efek samping yang tidak diinginkan, sebagai contoh petroleum atau petroleum jelly yang dapat bersifat toksik dan membentuk lapisan penutup (oclusif) yang ditujukan untuk mengunci kelembaban tetapi bila digunakan setiap hari akan menyebabkan efek samping dimana kulit bibir mengalami penurunan dalam mempertahankan kelembaban sehingga kulit bibir menjadi kering (Tricaesario, 2016). Untuk menghindari hal tersebut maka akan lebih aman jika digunakan emolien yang berasal dari alam. Emolien alam yang dapat digunakan dalam pembuatan sediaan lipbalm adalah lemak atau minyak yang berasal dari tumbuhan.
Bahan alam yang memiliki potensi sebagai emolien adalah biji kopi arabika java preanger. Kopi arabika java preanger merupakan kopi khas Jawa Barat yang telah ada sejak zaman penjajahan Belanda (Aziz, 2009). Kopi ini dianggap kopi special karena memiliki aroma dan tekstur yang khas sehingga sangat digemari oleh masyarakat eropa saat itu (Djuwendah E, dkk, 2018). Kopi arabika mengandunng kafein (Sukohar dkk, 2011), asam klorogenat, polisakarida, trigliserida dan asam lemak linoleate (Farhaty, 2015) Kandungan asam linoleate ini sekitar 40$45 \%$ yang dapat melembabkan kulit, meremajakan kulit dan juga melenturkan kulit (Simbolon dkk, 2013).

Berdasarkan latar belakang tersebut, penelitian ini bertujuan untuk membuat formulasi sediaan lipbalm dari ekstrak biji kopi arabika java preanger sebagai pengganti emolien sintetik yang aman, stabil dalam penyimpanan serta efektif sebagai emolien alami.

\section{METODE PENELITIAN}

\subsection{Alat}

Alat yang digunakan dalam penelitian ini adalah neraca analitik, blender, spatula, cawan porselen, pipet tetes, alumunium foil, kaca arloji, gelas kimia, batang pengaduk, alat soxhlet, gelas ukur, penangas air, lempeng, $\mathrm{pH}$ meter digital, kaca objek, rotary evaporator, skin analyzer.

\subsection{Bahan}

Bahan yang digunakan dalam penelitian ini adalah ekstrak biji kopi arabika java preanger yang diperoleh dari 
perkebunan kopi gunung manglayang Sumedang Jawa barat. cera alba (PT Bratacheum), gliserin (CV.Versajaya), propil paraben (CV. Versajaya), BHT (butil hidroksi toluen), vaselin album (CV. Versajaya) pereaksi dragendroff (Labtek), pereaksi mayer(Labtek), pereaksi steansy(Labtek), pereaksi $\mathrm{FeCl}_{3}(\mathrm{Labtek})$, serbuk $\mathrm{Mg}$, amil alkohol, kloroform, $\mathrm{HCl} 10 \%, \mathrm{NaOH} 1 \mathrm{~N}$, $\mathrm{Na}_{2} \mathrm{SO}_{4}, \mathrm{NaOH} 30 \%$, pereaksi Liebermen buchard, $\mathrm{H}_{2} \mathrm{SO}_{4}$, gelatin, eter dan asam asetat anhidrat (Labtek).

\subsection{Metode}

\subsubsection{Pengumpulan Bahan}

Biji kopi arabika java preanger diperoleh dari Gunung Manglayang, Desa Pengadean, Kabupaten Sumedang.

\subsubsection{Determinasi Tanaman}

Determinasi tanaman dilakukan di Lembaga Ilmu Pengetahuan Indonesia (LIPI) Bogor.

\subsubsection{Pembuatan Ekstrak Biji Kopi}

Biji kopi yang telah dikeringkan, digiling halus hingga berbentuk serbuk, lalu sampel dimasukan kedalam alat soxlet dengan pelarut $\mathrm{n}$ hexan. Ekstrak biji kopi yang didapat kemudian diuapkan menggunakan rotary evaporator (Lamona, 2018) untuk memisahkan ekstrak kopi dan pelarutnya sehingga mendapatkan hasil ekstrak kopi yang berwarna kecokelatan yang kemudian dapat digunakan pada formulasi sediaan lipbalm.

\subsubsection{Formula Sediaan Lipbalm}

Formula sediaaan lipbalm dibuat dengan variasi konsentrasi ekstrak kopi Arabika java preanger (3\%, 6\% dan 9\%) dengan satu formula sebagai basis tanpa ekstrak kopi.
Tabel. 1 Formula Sediaan Lipbalm (Nazliniwaty, 2019)

\begin{tabular}{lcccc}
\hline \multirow{2}{*}{ Bahan } & \multicolumn{4}{c}{ Formula } \\
\cline { 2 - 5 } & b & $\mathbf{f 1}$ & $\mathbf{f 2}$ & $\mathbf{f 3}$ \\
\hline Ekstrak kopi & - & 3 & 6 & 9 \\
Gliserin & 8 & 8 & 8 & 8 \\
Cera alba & 15 & 15 & 15 & 15 \\
Propil paraben & 0,2 & 0,2 & 0,2 & 0,2 \\
BHT & 0,02 & 0,02 & 0,02 & 0,02 \\
Vaselin album & ad5g & ada5g & ad5g & ad5g \\
\hline
\end{tabular}

\subsubsection{Pembuatan Sediaan Lipbalm}

Sediaan dibuat dengan melarutkan basis vaselin album, cera alba dilelehkan pada suhu lelehnya yaitu $62-65^{\circ} \mathrm{C}$ (campuran A), kemudian campuran propil paraben, BHT dan gliserin (campuran B) dimasukkan ke dalam lelehan basis sambil terus diaduk, lalu ketika suhu sudah tidak terlalu panas dimasukkan ekstrak biji kopi sambil diaduk. Setelah itu dimasukkan ke dalam cetakan yang telah diolesi gliserin lalu dibiarkan pada suhu ruangan sampai membeku.

\subsubsection{Uji Stabilitas Fisik}

Sediaan lipbalm kemudian di evaluasi meliputi pengujian organoleptic (warna, bau dan tekstur), homogenitas dilakukan dengan menggunakan cara mengoleskan sejumlah tertentu sediaan pada kaca transparan, pengukuran $\mathrm{pH}$ menggunakan alat $\mathrm{pH}$ meter yang telah dikalibrasi sebelumnya (Ratih dkk, 2014). uji titik leleh dilakukan dengan cara meletakkan lipbalm di dalam cawan penguap dan dileburkan di oven dengan suhu awal $50^{\circ} \mathrm{C}$ selama 15 menit, amati apakah melebur atau tidak, setelah itu dinaikan $1^{\mathrm{C}} \mathrm{C}$ setiap 15 menit dan diamati pada suhu ke berapa lipbalm mulai melebur (Haque, 2019).

\subsubsection{Uji Iritasi}

Uji iritasi dilakukan secara in vivo tanpa etical clereance dengan metoda 
Patch test terhadap punggung kelinci putih jantan. Pengujian dilakukan terhadap kelinci jantan ras New Zealand dengan bobot $3 \mathrm{~kg}$. Waktu pengamatan selama 72 jam, kemudian dihitung skor indeks iritasi primer kualitatif untuk menentukan tingkat iritasi setiap formula (Zulkarnain AK, dkk, 2013). Kelinci yang telah dicukur bagian punggungnya diaplikasikan sebanyak 0,5 gram formula lipbalm yang mengandung ekstrak biji kopi dan lipbalm yang tidak mengandung ekstrak biji kopi kemudian ditutup dengan menggunakan kassa. Parameter yang dilihat adalah eritema dan edema.

\subsubsection{Uji Efektivitas}

Uji efektivitas sediaan lipbalm yang mengandung Ekstrak Biji Kopi Arabika (Coffea arabica L.) java preanger dilakukan dengan menggunakan alat skin analyzer (Nazliniwaty, 2019). Pengujian ini dilakukan terhadap 20 orang sukarelawan (panelis) dengan kriteria wanita sehat umur 13-17 tahun., tidak sedang menggunakan lipbalm sebelum dan selama pengujian.

Sebelum dilakukan pengolesan pada bibir, terlebih dahulu diukur kadar air dan kadar minyak sukarelawan dengan menggunakan alat skin analyzer untuk mengetahui kondisi awal permukaan kulit bibir. Kemudiaan \pm 1 gram sediaan lipbalm dioleskan pada bibir sukarelawan. Sediaan ini digunakan setiap pukul 9 malam setiap hari selama satu bulan.

Setelah satu bulan bibir relawan diuji kembali dengan alat skin analyzer. Parameter yang diamati adalah kadar air dan kadar minyak. Selanjutnya nilai evaluasi tersebut diolah dengan menggunakan perhitungan statistika.

\section{HASIL DAN PEMBAHASAN}

Hasil determinasi yang dilakukan di Lembaga Ilmu Pengetahuan Indonesia (LIPI) bogor menunjukan bahwa tanaman yang digunakan dalam penelitian adalah spesies Coffea arabica L dengan nama lokal Kopi arabika java preanger yang berasal dari suku Gentianales (Handayani $R$, 2018).

Tabel 2. Hasil Evaluasi Fisik Sediaan

\begin{tabular}{lccc}
\hline \multirow{2}{*}{ Evaluasi } & \multicolumn{3}{c}{ Formula } \\
\cline { 2 - 4 } & $\mathbf{f 1}$ & $\mathbf{f 2}$ & $\mathbf{f 3}$ \\
\hline Organoleptik & & &
\end{tabular}

\begin{tabular}{lccc} 
a. Warna & $\mathrm{Ck}^{+}$ & $\mathrm{Ck}^{++}$ & $\mathrm{Ck}^{+++}$ \\
b. Bau & $\mathrm{Kk}$ & $\mathrm{Kk}$ & $\mathrm{Kk}$ \\
c. Tekstur & $\mathrm{Sp}$ & $\mathrm{Sp}$ & $\mathrm{Sp}$ \\
\hline Homogenitas & $\mathrm{H}$ & $\mathrm{H}$ & $\mathrm{H}$ \\
\hline $\mathrm{pH}$ & 6,59 & 6,51 & 6,47 \\
\hline Titik leleh & 55,3 & 55,5 & 55,8
\end{tabular}

Keterangan:

$\mathrm{Ck}^{+}$(coklat muda), $\mathrm{Ck}^{++}$(coklat tua), $\mathrm{Ck}^{+++}$(coklat sangat tua), Kk (khas kopi), Sp (semi padat), H (homogen).

Hasil evaluasi fisik terhadap sediaan lipbalm dari ekstrak kopi arabika java preanger dengan konsentrasi (3\%,6\% dan 9\%) menunjukan warna sediaan semakin tinggi konsentrasi ekstrak kopi, maka warnanya semakin coklat tua. Sedangkan ketiga formula memiliki bau khas kopi dengan konsistensi semi padat. Baik warna, bau maupun konsistensi tidak mengalami perubahan yang signifikan selama penyimpanan.

$\begin{array}{crr}\text { Hasil } & \text { pengamatan } & \text { terhadap } \\ \text { homogenitas } & \text { lipbalm } & \text { selama }\end{array}$
penyimpanan tidak ada perubahan yang signifikan dan menunjukan homogenitas yang baik. Hasil pengukuran pH diperoleh semakin tinggi konsentrasi ekstrak biji kopi, pH semakin menurun. Hal ini dikarenakan ekstrak biji kopi memiliki pH asam yaitu 3,5 dari asam klorogenat 
(Ardiansyah, 2019) dan semakin lama disimpan maka pH semakin menurun. Hal ini dikarenakan terjadi proses oksidasi selama penyimpanan. Tetapi hasil pengujiansi $\mathrm{pH}$ masih memenuhi syarat range $\mathrm{pH}$ kulit bibir yaitu 3,8-4,7 (Siregar, 2014).

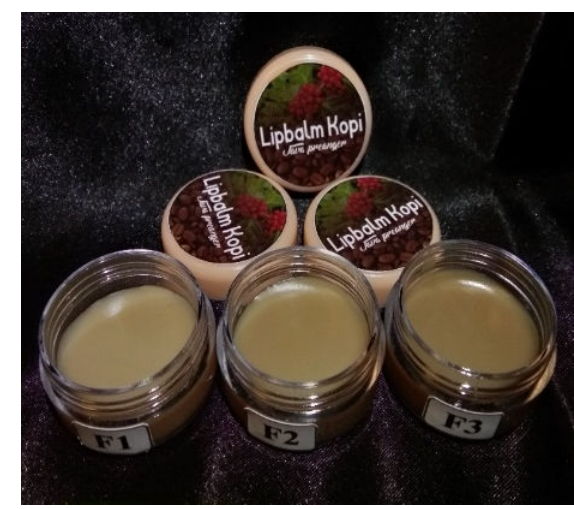

Gambar 1. Sediaan Lipbalm

Pengujian titik leleh diperoleh bahwa semakin tinggi konsentrasi ekstrak biji kopi titik leleh semakin naik mendekati titik leleh ekstrak biji kopi, semakin lama sediaan disimpan, titik leleh semakin turun. Pada uji titik leleh sediaan lipbalm ekstrak biji kopi didapatkan hasil memenuhi syarat titik leleh untuk lipstik sesuai SNI 16-47691998 yaitu $50^{\circ} \mathrm{C}-70^{\circ} \mathrm{C}$.

Hasil uji iritasi terhadap hewan dilakukan dengan metode patch test terhadap kelinci jantan ras New Zealand diketahui bahwa sediaan lipbalm yang diuji aman digunakan karena tidak menyebabkan iritasi pada kulit kelinci, tidak mengalami reaksi eritema maupun edema. Hal ini dikarenakan bahan aktif yang digunakan dalam formula merupakan bahan alam yang terbukti aman serta bahan tambahan yang terbukti aman, inert, tidak mengiritasi dan tidak toksik secara oral.
Tabel 3. Hasil Uji Efektivitas Lipbalm

\begin{tabular}{ccccc}
\hline \multirow{2}{*}{$\begin{array}{c}\text { Relaw } \\
\text { an }\end{array}$} & \multicolumn{2}{c}{ Kadar Air (\%) } & \multicolumn{2}{c}{$\begin{array}{c}\text { Kadar Minyak } \\
\text { (\%) }\end{array}$} \\
\cline { 2 - 5 } & $\begin{array}{c}\text { Sebelu } \\
\text { m }\end{array}$ & $\begin{array}{c}\text { Sesud } \\
\text { ah }\end{array}$ & $\begin{array}{c}\text { Sebelu } \\
\text { m }\end{array}$ & $\begin{array}{c}\text { Sesud } \\
\text { ah }\end{array}$ \\
\hline 1 & 44,7 & 48,0 & 20,2 & 21,5 \\
\hline 2 & 32,8 & 35,9 & 15,1 & 16,1 \\
\hline 3 & 33,4 & 40,5 & 14,3 & 18,2 \\
\hline 4 & 39,7 & 45,5 & 17,8 & 20,4 \\
\hline 5 & 35,9 & 41,6 & 16,1 & 18,6 \\
\hline 6 & 43,9 & 52,1 & 19,7 & 24,4 \\
\hline 7 & 44,3 & 44,6 & 20,7 & 18,4 \\
\hline 8 & 38,6 & 42,6 & 17,3 & 18,4 \\
\hline 9 & 39,0 & 43,6 & 17,5 & 19,5 \\
\hline 10 & 39,5 & 43,7 & 17,7 & 19,6 \\
\hline 11 & 36,8 & 40,5 & 16,5 & 18,1 \\
\hline 12 & 35,5 & 38,2 & 15,9 & 17,1 \\
\hline 13 & 35,6 & 48,1 & 12,3 & 21,6 \\
\hline 14 & 31,9 & 45,9 & 14,3 & 20,6 \\
\hline 15 & 40,8 & 50,6 & 18,3 & 22,7 \\
\hline 16 & 43,1 & 48,3 & 19,3 & 21,6 \\
\hline 17 & 41,5 & 44,0 & 18,6 & 19,7 \\
\hline 18 & 30,5 & 42,1 & 13,6 & 18,9 \\
\hline 19 & 41,4 & 42,1 & 19,1 & 18,9 \\
\hline 20 & 30,9 & 40,7 & 13,8 & 18,3 \\
\hline & & & & \\
\hline
\end{tabular}

Keterangan:

Kadar air normal

: $40 \%-60 \%$

Kadar minyak normal:
1. Dry Skin
: $8 \%-18 \%$
2. Neutral Skin
: $18 \%-30 \%$
3. Oily Skin
: 30\%-40\%

Hasil uji efektivitas sediaan lipbalm yang mengandung ekstrak biji kopi arabika (Coffea arabica L.) java diperoleh bahwa sediaan lipbalm yang mengandung ekstrak kopi arabika (Coffea arabica L.) java preanger menaikkan kelembaban bibir baik kadar air maupun kadar minyak.

\section{KESIMPULAN}

Berdasarkan hasil penelitian diperoleh kesimpulan hasil evaluasi sediaan lipbalm dengan bahan aktif biji kopi arabika (Coffea arabica L.) java preanger diperoleh formula F3 dengan konsentrasi ekstrak kopi $9 \%$, gliserin $8 \%$, cera alba $15 \%$, propil paraben $0,2 \%$ dan BHT 0,02\% merupakan formula yang paling aman tidak menyebabkan iritasi, stabil dalam penyimpanan, dan 
memberikan efektivitas emolien terhadap bibir dengan menaikan kelembaban bibir.

\section{UCAPAN TERIMA KASIH}

Terima kasih kepada program studi Farmasi Fakultas Matematika dan IImu Pengetahuan Alam Universitas Garut atas dukungan fasilitas selama melakukan penelitian ini.

\section{DAFTAR PUSTAKA}

Agustiana YD dan Herliningsih., 2019. Formulasi Sediaan Lipbalm dari Minyak Zaitun (Olive oil) sebagai Emolien dan Penambahan Buah Ceri (prunus avium) sebagai Pewarna Alami, Jurnal of Herbs and Farmacological, 1(1): $24-31$

Ardiansyah D, Tjota H dan Kiyat WE., 2019. Review : Peran Enzim dalam Meningkatkan Kualitas Kopi, Jurnal IImu Pertanian, Kehutanan dan Agroteknologi, 19(2): 86 - 91

Aziz T, Cindo R dan Fresca A., 2009. Pengaruh Pelarut Heksana Dan Etanol, Volume Pelarut, Dan Waktu Ekstraksi Terhadap Hasil Ekstraksi Minyak Kopi, Jurnal Teknik Kimia, 16(1): 1 - 8

Djuwendah E, Karyani T, Sadeli AH dan Kusno K., 2018. Agroindustrialisasi Kopi Arabika Java Preanger di Desa Margamulya Kecamatan Pangalengan Kabupaten Bandung, Jurnal Agribisnis dan Sosial Ekonomi Pertanian, 3(1): 359 - 426

Farhaty N dan Muchtaridi., 2016. Tinjauan Kimia dan Aspek Farmakologi Senyawa Asam Klorogenat Pada Biji Kopi : review, Jurnal Farmaka, 14(1): 214 - 227

Handayani R, Auliasari N, Octaviany TK, Hindun S dan Sriarumtias FF., 2019. Formulation and Evaluation of Body Splash from Java Preanger Arabica coffee (Coffea arabica L.) Oil, Jurnal of Physics: Conference Series, IOP Publishing 1402 (055092)

Haque AF dan Sari Dr., 2019. Formulasi Lipbalm Minyak Atsiri dari Kulit Jeruk Kalamansi (x Citrofortunella microcarpa), Jurnal Ilmiah Farmacy, 6(2): 385 - 392
Lamona A dan Nurman S., 2018, Preliminary Study of The Component of Arabica Cofee Been Oil (Coffea arabica L) From Bener Meriah Regency, Aceh Province Using GC-MS, Jurnal Agriovet, 1(1): 61 72

Nazliniwaty, Laila L dan Wahyuni M., 2019. Pemanfaatan Ekstrak Kulit Buah Delima (Punica granatum L) dalam Formulasi Sediaan Lipbalm, Jurnal Jamu Indonesia, 4(3): 87 - 92

Putra S dan Ferry Y., 2015. Keragaan Kopi Arabika Java Preanger di Jawa Barat, Balai Penelitian Tanaman Industri dan Penyegar, SIRINOV, 3(3): $113-126$

Ratih H, Titta H dan Ratna CP., 2014. Formulasi Sediaan Lip Balm Minyak Bunga Kenanga (Cananga oil) sebagai Emolien, Prosiding Simposium Penelitian Bahan Obat Alami (SPBOA) XIV dan Muktamar XII PERHIPBA 2014, Yogyakarta ; Leutikaprio. Hal 3

Simbolon B, Pakpahan K dan MZ Siswani., 2013. Kajian Pemanfaatan Biji Kopi (Arabika) sebagai Bahan Baku Pembuatan Biodiesel, Jurnal Teknik Kimia USU, 2(3): 44 - 50

Siregar YDI dan Utami P., 2014. Pemanfaatan Extrak Kulit Melinjo Merah (Gnetum Gnemon) sebagai Pewarna Alami Pada Pembuatan Lipstik, Jurnal Kimia Valensi, 4(2): 98 - 108

Sukohar A, Setiawan, Wirakusumah FF dan Sastramihardja HS., 2011. Isolasi dan Karakterisasi Senyawa Sitotoksik Kafein dan Asam Klorogenat dari Biji Kopi Robusta Lampung, Jurnal Medika Planta, 1(4): 11 - 26

Tricaesario C dan Widayati Rl., 2016. Efektivitas Krim Almond Oil 4\% terhadap Tingkat Kelembaban Kulit, Jurnal Kedokteran Diponegoro, 5(4): 599 - 610

Yusuf NA, Hardianti B, Lestari IA dan Sapra A., 2019. Formulasi dan Evaluasi Lipbalm Liofilisat Buah Tomat (Solanum lycopersicum L.) Sebagai Pelembab Bibir, Jurnal Ilmiah Manuntung, 5(1): 115 - 121 Zulkarnain AK, Susanti M dan Lathifa AN., 
Formulasi Sediaan Lipbalm Dari Ekstrak Biji Kopi...

2013. Stabilitas Fisik Sediaan Lotion O/W dan W/O Ekstrak Buah Mahkota Dewa sebagai Tabir Surya dan Uji Iritasi Primer
Pada Kelinci, Traditional Medicine

Journal, 18(3): 141 - 150

Copyright $\odot \mathbf{2 0 2 0}$ The author(s). You are free to Share - copy and redistribute the material in any medium or format. Adapt - remix, transform, and build upon the material. Under the following terms: Attribution - You must give appropriate credit, provide a link to the license, and indicate if changes were made. You may do so in any reasonable

manner, but not in any way that suggests the licensor endorses you or your use. Non Commercial - You may not use the material for commercial purposes. Sharealike - If you remix, transform, or build upon the material, you must distribute your contributions under the same license as
apply legal terms or technological measures that legally restrict others from doing anything the license permits. 